\title{
An Analysis of Women-Centered Care Needs in Midwifery Care
}

\author{
Fitria Siswi Utami ${ }^{1}$, Intan Mutiara Putri ${ }^{2}$ \\ \{fitriasiswi@unisayogya.ac.id ${ }^{1}$ \} \\ Midwifery Department, Faculty of Health Sciences, 'Aisyiyah Yogyakarta University, Indonesia ${ }^{1,2}$
}

\begin{abstract}
An ideal health care service recommend a women-centered care approach to midwifery services. A concept which is. The study was conducted to explore the midwives and patients perspectives on women center care. A phenomenology qualitative design $(n=12)$ were purposively drawn at midwifery care unit of one private hospital in Yogyakarta Province, Republic of Indonesia. The result explain that there are three themes representing midwives and women's perspectives on women center care in midwifery services. These were midwifery services capacity, empowerment, and challenge. Within these themes, sub themes arose that represent key elements of women center care. These were patient's rights and liabilities, excellent service, the number of health care provider, health insurance, instruments, education, awareness, and training.
\end{abstract}

Keywords: Women-centered care, Midwifery care

\section{Introduction}

Health care services which focused on physical condition means override some factors related the definition of health. Quality of life, personality, social, even stages of life are needed to have more attention in order to improve the quality of health care services [1]. Furthermore, health professional education also introduces the skill of developing social relationship in the curriculum intend to be able to do professional integrated assessment to their client. Ideally, the knowledge that given by the lecturer at the education institution can be practiced by the student at the clinical setting as well. It means that a good collaboration is needed between health education institution and health care services [2].

An innovation of health care services related to holistic care services especially women's health became an issue regarding to improving the quality of women's health. A midwife be expected to adjust midwifery philosophy of midwifery care specifically women center care, a concept that a woman is entitled to serve in a holistic manner which is cover social, emotional, spiritual, physical, and cultural in every stage of women's life cycle [3].

Recently, health policy increasingly focused on individual service based on individual needs. The concept of women-centered care has been used as a framework in various policy documents and standards related to midwifery services, especially in the United Kingdom and Australia [4]. Moreover, the concept of women-centered care consist of several main components i.e. health care services respond to the unique needs of women and respect their ethnic, cultural, social, and family background; the woman should be involved in arranging midwifery care plans for their needs by health care professional who their known; the woman 
should be provided with sufficient information for their midwifery care plans; women's psychological and physical needs must be understood and their autonomy is respected.

A survey conducted in Australia found that women and midwives providing womencentered care as a center of the way to do their responsibilities. The model ensuring that women have control over to the midwifery care for them, focus on their needs, and accept the different approach is a part of women-centered care model. Being flexible in parenting and family support roles is a component of this model as well.

Maputle [5] explain that the concept of women-centered care consists of (1) caring focus on individual, (2) sharing responsibility, reciprocity, good communication, and acceptance, (3) empowerment, (4) sharing information, interdependence, and collaboration, (5) decision making involvement, (6) autonomy, (7) respect for culture, ethnicity, social, and family background, (8) holistic care, (9) serenity and safety.

Currently, innovation on women's health care services evolve on aesthetic services in Indonesia. This is appealing to support the need for biopsychosocial services for women, not only focus on physical but also concern to another aspects of health. Understanding and the need of women-centered care concept are important to be assessed as a basis for determining the women's health care services improvement.

\section{Method}

The study was conducted to explore women center care from midwives and patients' perspectives. A phenomenology qualitative design was chosen as a representative design in order to achieve the objective of the study. 12 participants were recruited including 7 midwives and 5 patients by using purposive sample method. The data was collected by focus group discussion and interview by the researcher. The data was recorded, transcribed and checked by the researcher.

Ethical approval of the study was granted by the health research ethics committees of 'Aisyiyah Yogyakarta University. The purpose of the study was further explained to all prospective participants, including potential benefits and harms, and they were asked if they willing to take a part. All participants being interviewed provided informed consent prior to commencing the interview.

Interviews were audio recorded, anonymized to ensure confidentiality and transcribed verbatim and checked by the research team for accuracy. Thematic analysis was used incorporating a framework analysis approach.

\section{Results and Discussion}

The result of qualitative data analysis following focus group discussion and interviews found three major themes which is represent midwives and women's perspectives on womencentered care. The three main themes were: midwifery services capacity, empowerment, and challenge for women-centered care. Table 1 show at Thematic Framework. 
Table 1. Thematic Framework

\begin{tabular}{ll}
\hline Theme & Subtheme \\
\hline Midwifery services capacity & Patient's rights and liabilities \\
& Excellent services \\
\hline Empowerment & The number of health care provider \\
& National health coverage regulation \\
\hline Challenge & Education \\
& Awareness \\
& Instruments \\
& Training \\
\hline
\end{tabular}

\subsection{Midwifery services capacity}

This theme describes the finding from the data that the midwives tried to give information for all patient's rights and liabilities. The midwife provide information related to the step that they have to conduct to do as midwifery care based on the assessment and the diagnoses of their cases. Moreover, all the things that the patient have to do and accept during the caring process is informed as well. It reflects how midwife try to give the services using the philosophy of women-centered model. Women's involvement is being practiced during the process.

Patient in maternity ward as participant in this study confirm that they feel more comfortable and satisfied when they get more information from the midwife related their condition and anything that they have to do and accept during the services. For instance, patient involvement was identified as a part of the way to give an excellent service. The number of strategies were identified to serve with an excellent service including helping the woman to making a decision based on their condition, giving more information, respecting their reaction, and understanding their background. This midwife notes the response from the patient when they give an adequate information to the woman and their family:

"They look more satisfied and concern with their condition as well as I can see that they pay more respect to us. Sometimes, I can see that the woman fell familiar with the midwife even we know each other at the first meet" (Midwife-1).

This participant reflects the way how the midwife provides an excellent service in order to improve patient satisfying level. This midwife mentions an identifying the need of the woman as apart to support the patient's right:

"I understand that every patient really wants to get the best service from us. That's the reason for me to help them assess their needs and help them how to making a decision" (Midwife-3).

The feeling of satisfying was described by some mothers as participant in this study. They identified that respect and good service meant being helping the mother to be recognized as an individual with various experience and background:

"The midwife really helps me; they explain anything that I have to do. Even I said that this is not my first experience being pregnant mother, they stand on me and try to assess more information about me and help me to making the best decision for me and my baby" (Woman1).

"I don't think that the midwife will provide the best service for me because I use national health coverage and don't pay to the hospital directly" (Woman-4).

"And like that I don't feel that the midwife tries to do something based on what they want to do, they give us what we need based on their interview to us" (Women-5). 
The theme midwifery service capacity for women-centered care analysis in this study describes how the midwives' respects on women's right and liabilities and how the women's feel on the services. Both are components of women-centered care concept in midwifery services.

\subsection{Empowerment}

Theme of empowerment in women-centered care illustrates how empowerment as a soul of women-centered care concept. However, this study found that some reasons to support women's empowerment are unpredictable and possible to do related to some weakness of the services. The subtheme of empowerment in this study mention two big issues related health care service in Indonesia, that are the number of health care provider and the regulation of national health coverage.

The sub theme, number of health care provider, describes how the resources in maternity ward are faced with some difficulties to provide best performance in their work. The number of midwives is compared with the amount of work to be done was their limitation to do their best performance. The midwives try to improve women and family empowerment regarding their limitation number. The midwives in this study describe that they have to do a lot of work with high number of patient otherwise the number of midwives who work is limited:

"We work for labor room and postpartum ward. There are 2 to 3 midwives for every work shift. Sometimes we ask the family of the patient to help them to do some services. We think that this is the way how to do family empowerment, but I feel like a bad midwife for them, because I need to do another work and ask them to do my work indeed" (Midwife-1).

"sometimes we did not pay attention to the patient at the postpartum ward because we busy with the patient at labor room, especially when we have an emergency case in labor room or when we have full bed patient in labor room" (Midwife-2).

"I ever ask the family members to observe the woman's contraction during the labor process because all beds are full with the patient at that time. I'm not sure, this is the correct way to involve the family members or this is the bad thing that I have done" (Midwife-5).

The illustration related to the number of the health care provider is mentioned by the women as well:

"mmm...., actually I ever thought that the midwife are busy with their work, so... they ask my husband to help me when I would like to go the restroom" (Women-2).

"my mom said pity of them (the midwife) with their work. There are only 3 and we are more than 10. How they work with their hands?" (Woman-4).

"They asked my husband to observe my uterine contraction even we said that we didn't have any experience before, but I think this is something normal to do because impossible to ask them stand by me all the time" (Women-5).

The theme of empowerment also mentions about the national health insurance. This is mention by the patient:

"I thought that they didn't help me and ask my husband to do because we use National Health Insurance. So, they gave different service for us. However, I'm so surprise because finally I know that my husband can help me very well even we didn't have any experience before" (Woman-2).

"We don't pay to the hospital; we use the National Health Coverage. So, I think that this is normal to get different services than others" (Woman-4). 
The theme of empowerment in this study describes two points, i.e. National Health Insurance and the number of health care provider. Both are issues which making the value of empowerment become having different point of view when we have a look from different side.

\subsection{Challenge}

This theme illustrates how the concept of women-centered care is a challenge. This theme also describes how women-centered care needs some improvement in the management system of the hospital. This theme comprises four sub themes; that are, education, awareness, instrument, and training. The sub themes in this theme is linked each other. Participants in this study mention that lack of understanding about the concept bringing to difficulties to provide a holistic care midwifery care.

The sub theme, education, describes how limited the services are when the midwife could not give how to do holistic care which cover physical, psychological, social, and cultural condition of the patient. Participants explain how the need to improve their knowledge and skill:

"Mostly, we are on Diploma 3 of Midwifery, there is only 1 midwife who graduate from master degree. We don't have any chance to study. Sometimes, I fell lazy to continue my study at the university to get higher degree" (Midwife-1).

"Women-centered care?? What it is... I didn't get any information about this during my study at Diploma 3" (Midwife-2).

"Yaaaa... I ever heard about women-centered care before. I think that we already serve the patient using these concept, but not sure actually" (Midwife-4).

An issue related awareness is described by the participants:

"Tired, many things to do, how we can give a holistic care" (Midwife-5).

"I want to an excellent service actually, but there are many things that I have to do during the working time. So, as long as we can observe and caring the patient to help them being healthy mother, we serve them in a right way" (Midwife-2).

These theme describes how the midwife doing an assessment and midwifery care based on habit or routine activity that they do based on the cases:

"yaa..., we use the form in medical record to assess the patient and then we make the midwifery care plans as usual and based on the condition of the patient that we get from the assessment process" (Midwife-1).

"We give the midwifery care based on Standard of Procedure that we have in this hospital. Maybe when we have the instrument that make our work getting easier it's will help" (Midwife3).

Training is a sub theme which is explain in this theme by the participant as a solution for the limitation of chance to continue their study to the next level:

"I think training will be help us to update our knowledge and skill" (Midwife-1).

"Maybe training......so we can learn something new and not too stupid. hahaha..." (Midwife-2)

\subsection{Discussion}

This study explores the concept of women-centered care from the midwives and women's perspectives. The analysis indicates themes that women-centered care is a concept which is needs in order to improve the quality of midwifery services and enhance women's quality of health. The findings of this study illustrate how women-centered care could potentially be 
achieved, but some barriers were describing how the midwife and patient difficult to achieve the concept.

World Health Organization mention that spirituality is an important dimension in a quality of life. How spiritual well-being of the patient could be assessed to help the midwife to giving a holistic care for the women [1]. It is important because spiritual well-being is connected to the ability to coping with their problem and helping the recovery process [6]. The concept of spiritual well-being is explained in Table 2.

Table 2. Classification of spiritual and religious measurement domains in health care

\begin{tabular}{|c|c|}
\hline Measurement Domain & Example \\
\hline Religiosity & $\begin{array}{l}\text { Strength of belief, prayer and worship practices, intrinsic } \\
\text { versus extrinsic }\end{array}$ \\
\hline Spiritual/religious copping and support & $\begin{array}{l}\text { Response to stress in terms of spiritual language, } \\
\text { attitudes, practices, and sources of spiritual support }\end{array}$ \\
\hline Spiritual well-being & $\begin{array}{l}\text { Spiritual state or level of spiritual distress as a dimension } \\
\text { of quality of life }\end{array}$ \\
\hline Spiritual needs & Conversation, prayer, ritual; over what spiritual issues? \\
\hline
\end{tabular}

The result of the study shows that continuing a study to the next degree among the midwives is a problem which is lead to the next problem to understand and practice the concept of womencentered care midwifery care. The roadmap of human resources development is indicated become a solution to improve the quality of services for women. The midwife in Diploma 3 level of education means that they doing midwifery care because they know how to do the caring process as mentioned in KKNI level of competency qualification. They need become a professional midwife which is standard in bachelor degree and continuing to the profession level in accordance with the Indonesian midwifery constitution.

From the women point of view, the concept of women-centered care is a concept which they need to achieve a maximum level of women's health. The understanding of National Health Coverage is needed to avoid misunderstanding between health care provider, patient, and family member.

\section{Conclusion}

The results of this study indicates that understanding, awareness, policy, planning, and development is needed to conduct in order to enhance the service quality and women's health. Women-centered care is a concept which help women and midwife to understand each other easier and better. A good relationship between the health care provider and the patient during the maternity process is the most commonly expressed expectations from both side, the health care provider and the patient doing so.

\section{References}

[1] D. T. Wade and P. W. Halligan, "The biopsychosocial model of illness: A model whose time has come," Clin. Rehabil., vol. 31, no. 8, pp. 995-1004, 2017, doi: 10.1177/0269215517709890.

[2] Y. P. Susani, G. R. Rahayu, R. Sanusi, Y. S. Prabandari, and H. Mardiwiyoto, "Developing a Model 
of Professional Identity in Medical Students: the Role of Motivation and Participation," J. Pendidik. Kedokt. Indones. Indones. J. Med. Educ., vol. 7, no. 3, p. 159, 2018, doi: 10.22146/jpki.41831.

[3] Y. Yanti, M. Claramita, O. Emilia, and M. Hakimi, "Students' understanding of 'Women-Centred Care Philosophy' in midwifery care through Continuity of Care (CoC) learning model: A quasiexperimental study," BMC Nurs., vol. 14, no. 1, pp. 1-7, 2015, doi: 10.1186/s12912-015-0072-z.

[4] H. L. McLachlan et al., "COSMOS: COmparing Standard Maternity care with one-to-one midwifery support: A randomised controlled trial," BMC Pregnancy Childbirth, vol. 8, pp. 1-12, 2008, doi: 10.1186/1471-2393-8-35.

[5] M. S. Maputle and H. Donavon, "Woman-centred care in childbirth: A concept analysis (Part 1).," Curationis, vol. 36, no. 1, pp. E1-8, May 2013, doi: 10.4102/curationis.v36i1.49.

[6] A. Hunter, D. Devane, C. Houghton, A. Grealish, A. Tully, and V. Smith, "Woman-centred care during pregnancy and birth in Ireland: Thematic analysis of women's and clinicians' experiences," $B M C$ Pregnancy Childbirth, vol. 17, no. 1, pp. 1-11, 2017, doi: 10.1186/s12884-017-1521-3. 